\title{
Corneal sensitivity after topical bromfenac sodium eye-drop instillation
}

This article was published in the following Dove Press journal:

Clinical Ophthalmology

16 April 2013

Number of times this article has been viewed

\author{
Kaori Yanai' \\ Jane Huang' \\ Kazuaki Kadonosono ${ }^{2}$ \\ Eiichi Uchio' \\ 'Department of Ophthalmology, \\ Fukuoka University School \\ of Medicine, Fukuoka, Japan; \\ ${ }^{2}$ Department of Ophthalmology, \\ Yokohama City University Medical \\ Center, Yokohama, Japan
}

Correspondence: Eiichi Uchio

Department of Ophthalmology, Fukuoka University School of Medicine,

7-45-I Nanakuma, Jonan-ku,

Fukuoka 8I4-0I80, Japan

$\mathrm{Tel}+8192801$ I0I I

Fax +8I 928654445

Email euchio@fukuoka-u.ac.jp
Purpose: To evaluate the safety of bromfenac sodium eye drops from the standpoint of corneal sensitivity and tear secretion in healthy controls following instillation for 1 month.

Methods: A prospective single-blind parallel clinical study was conducted in 20 eyes of ten healthy volunteers with no history of ocular or systemic allergic disease, dry eye, contact lens wear, or ocular surgery. Participants were instructed to instill either bromfenac sodium or artificial tears in each eye twice daily for 28 days. Corneal sensitivity tested using a Cochet-Bonnet esthesiometer was evaluated before and immediately after instillation at 7, 14, and 28 days after the initiation of treatment. Tear secretion was also evaluated by Schirmer's eye test before and at 28 days.

Results: No significant difference in mean corneal sensitivity and tear-secretion rate was observed between the bromfenac and artificial-tear treatment groups at any time.

Conclusion: These results indicate that bromfenac sodium eye drops are safe with respect to corneal sensitivity and tear secretion in subjects with a normal ocular surface condition. Further evaluation is still necessary to determine whether bromfenac is safe in pathological conditions, such as inflammatory disorders and postsurgical cases.

Keywords: bromfenac sodium, cornea, sensitivity, tear, nonsteroidal anti-inflammatory drug

\section{Introduction}

Several studies have shown that treatment with nonsteroidal anti-inflammatory drugs (NSAIDs) is effective for the control of inflammatory ocular surface disorders ${ }^{1-3}$ by directly reducing the biosynthesis of prostaglandins and indirectly reducing the production of leukotrienes. ${ }^{4}$ NSAIDs decrease hyperreactivity of inflammatory cells, such as mast cells and lymphocytes, during reepithelialization after keratoconjunctival inflammation, and lead to suppression of fibroblasts and vascular endothelial cells. ${ }^{5,6}$ Bromfenac sodium, a previously developed NSAID, was released in the United States in 1997, and is potent and long-acting compared to indomethacin, a peripheral analgesic compound possessing anti-inflammatory, antipyretic, and prostaglandin synthetaseinhibiting properties. ${ }^{7}$ It is reported that $0.1 \%$ bromfenac sodium eye drops are effective for the treatment of allergic conjunctivitis. ${ }^{8}$ Although it has been reported that bromfenac sodium has the strongest potency in inhibiting prostaglandin $\mathrm{E}_{2}$-induced aqueous flare among NSAIDs, ${ }^{9}$ its role in the treatment of ocular allergic disorders has not been examined in experimental or clinical studies. However, several cases of corneal perforation after bromfenac sodium ocular treatment have been reported..$^{10,11}$

Although a significant decrease of corneal sensitivity by diclofenac sodium eye drops in healthy people was reported in several studies, ${ }^{12,13}$ no study has thus far 
conducted a moderate-term observation of safety of the use of bromfenac sodium eye drops in humans. The aim of this study was to evaluate the safety of moderate-term instillation of bromfenac sodium eye drops in healthy volunteers, with special reference to corneal sensitivity and lacrimal secretion.

\section{Materials and methods}

\section{Participants}

We studied 20 eyes of ten healthy volunteers (seven men and three women). Subjects with a history of ocular or systemic allergic disease, dry eye, contact lens wear, or ocular surgery were excluded from this study. Also excluded were patients with infective conjunctivitis and those taking any systemic medication likely to affect ocular symptoms during the course of this study. Age ranged from 31 to 44 years, with a mean of 37 years.

\section{Study design}

Participants were instructed to instill either bromfenac sodium or artificial tears in each eye twice daily at 8 am and 8 pm for 28 days. Bromfenac sodium contains benzalkonium chloride as a preservative, and we used Soft Santear artificial tears (Santen Pharmaceutical, Osaka, Japan), which are preservative-free eye drops. Although the ophthalmologist was blinded to which side the test drugs were instilled, participants were aware of the side of tested drugs. Corneal sensitivity tested using a Cochet-Bonnet esthesiometer (Luneau Ophtalmologie, Chartres, France) was evaluated before and immediately after instillation at 7,14 , and 28 days after the initiation of treatment. Tear secretion was also evaluated by the Schirmer's eye test before and at 28 days. On each visit, clinical assessment of symptom severity and ophthalmological examination were performed. This study was carried out in July 2007, when typical seasonal allergic conjunctivitis was rare in Japan. This research adhered to the principles of the Declaration of Helsinki for research involving human subjects. Written informed consent was obtained from all participants.

\section{Statistical analysis}

Nonparametric tests were used to compare tested values between both treatments at baseline and other times, using the Mann-Whitney $U$-test. All tests were two-tailed, with significance set at the 0.05 level.

\section{Results}

\section{Corneal sensitivity}

Values of corneal sensitivity to bromfenac sides at the baseline point, 30 minutes, 1 week, 2 weeks and 4 weeks after entry were lower than those of the control side; however, there was no statistically significant difference (Figure 1) between the bromfenac and control sides.

\section{Tear secretory function}

Tear secretory function evaluated by the Schirmer's eye test before and at 28 days is shown in Figure 2. A tendency for a slight increase was observed on both sides. However, no significant differences were found between the sides receiving bromfenac and artificial tears at either time, and no time-dependent change was observed in either treatment group.

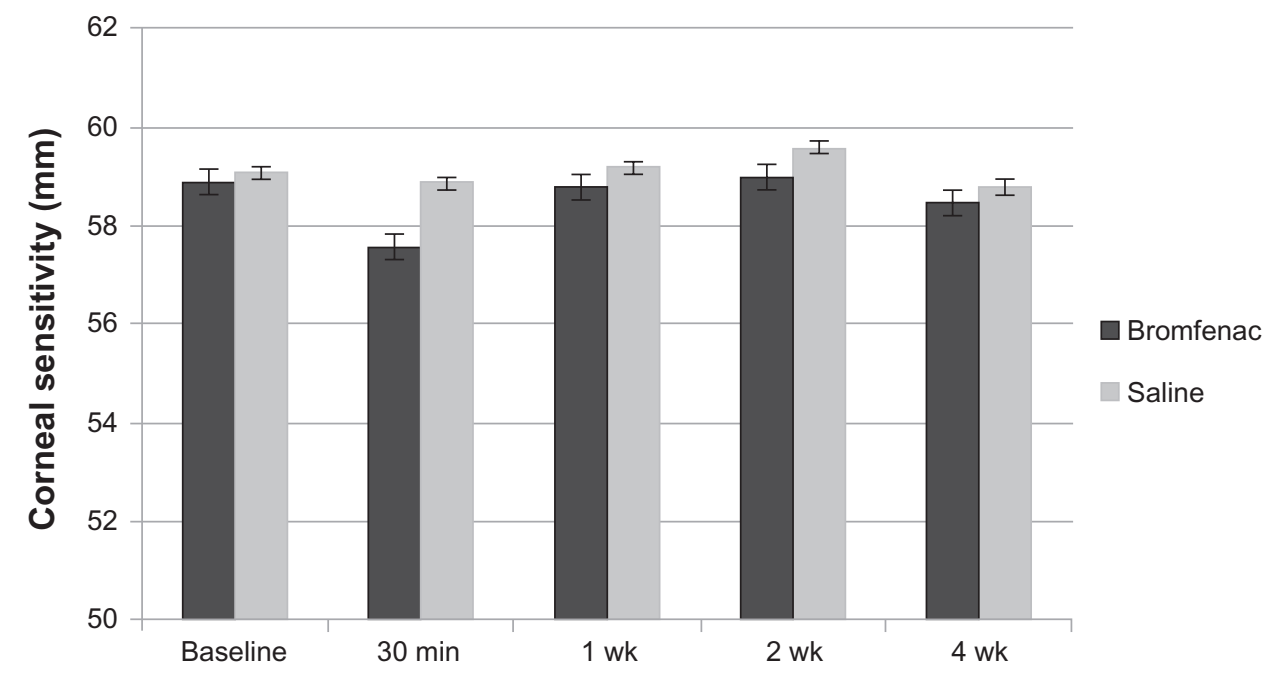

Figure I Sequential changes in corneal sensitivity in bromfenac sodium eye drops and control groups. Note: No significant difference between the two sides was observed at any time. 


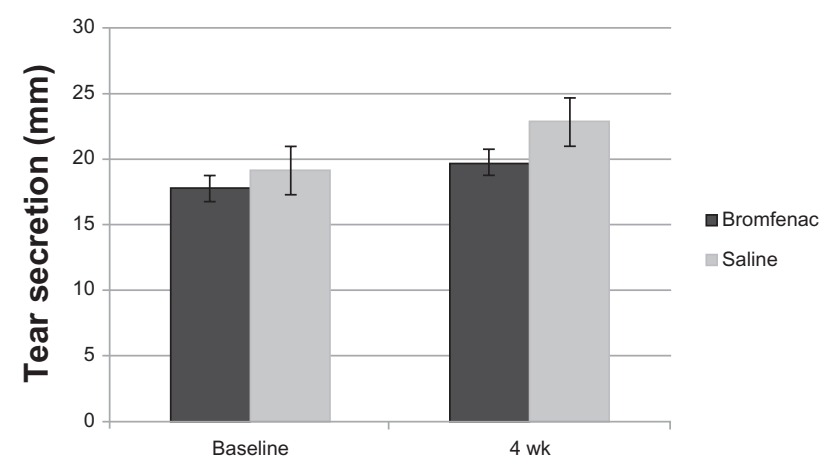

Figure 2 Tear secretion in bromfenac sodium and artificial-tear eye-drop groups. Note: A significant difference between the two groups was observed.

\section{Adverse effects}

No clinically important side effects, including contact blepharitis, corneal epithelial disorders, or systemic complications, such as hepatitis, were observed in any participants throughout the study period.

\section{Discussion}

The bromfenac sodium capsule was submitted for US Food and Drug Administration review for the short-term management of acute pain in 1994, and was approved and launched in July 1997 for this indication. However, prolonged use of bromfenac induced several cases of severe hepatotoxicity ${ }^{14}$ or fatal fulminant hepatitis. ${ }^{15}$ Based on these case reports, the bromfenac sodium capsule (Durac) was voluntarily withdrawn from sale by the manufacturer in 1998. In contrast, no case of fatal side effect has been reported in patients using bromfenac sodium eye drops. Corneal melt after instillation of bromfenac sodium eye drops has been reported. ${ }^{10,11}$ Important factors in those cases were old age and a history of previous ocular surgery or corneal disease, such as bullous keratopathy, bacterial corneal ulcer, or Stevens-Johnson syndrome. We have reported that the long-term use of bromfenac sodium eye drops for more than 1 year in patients with vernal keratoconjunctivitis induced no local or systemic side effects, and it was effective for controlling vernal keratoconjunctivitis. ${ }^{16}$ In the present study, it was confirmed that bromfenac sodium eye drops were safe and did not induce any apparent corneal side effects (with respect to corneal sensation and tear secretion), especially in eyes with a normal condition. The relatively lower incidence of adverse effects with bromfenac eye drops compared with other NSAID eyedrops such as diclofenac may be due to their aforementioned safety. However, NSAID eye drops may cause corneal complications in pathological conditions, such as postsurgical cases or corneal epithelial disorders, and careful observation is still necessary in these conditions. Because the sample size of this study is relatively small and only relatively young people were enrolled, the significance of these results could be limited in older patients and in postsurgical patients. Although the difference in corneal sensitivity between the two types of eye drops did not reach significance at any time point, there is a possibility that the difference may have been due to the difference of preservative in those eye drops. NSAID eye drops may cause not only corneal complications but also may induce anaphylactic reaction due to their aspirin-like property. NSAID eye drop-induced asthma attacks have been reported in patients with aspirin sensitivity, ${ }^{17,18}$ and NSAID eye drops should not be given to patients with asthma or aspirin sensitivity unless the patient is known to tolerate NSAIDs without trouble. Considering the previously reported side effects, particularly in those with preexisting ocular surface disorders, clinicians should take special care in long-term observation of patients with chronic use.

\section{Acknowledgments}

This work was supported by a Grant-in-Aid for Encouragement of Scientists (15591869) from the Ministry of Education, Science, Sports and Culture of Japan. We thank Dr W Gray for editing this manuscript.

\section{Disclosure}

The authors report no conflicts of interest in this work.

\section{References}

1. Gupta S, Khurana AK, Ahluwalia BK, Gupta NC. Topical indomethacin for vernal keratoconjunctivitis. Acta Ophthalmol (Copenh). 1991;69:95-98.

2. Laibovitz RA, Koester J, Schaich L, Reaves TA. Safety and efficacy of diclofenac sodium $0.1 \%$ ophthalmic solution in acute seasonal allergic conjunctivitis. J Ocul Pharmacol Ther. 1995;11:361-368.

3. Tauber J, Raizman MB, Ostrov CS, et al. A multicenter comparison of the ocular efficacy and safety of diclofenac $0.1 \%$ solution with that of ketorolac $0.5 \%$ solution in patients with acute seasonal allergic conjunctivitis. J Ocul Pharmacol Ther. 1998;14:137-145.

4. Ilic J, Gigon S, Leuenberger PM. Comparison of the anti-inflammatory effect of collyria of dexamethasone and diclofenac. Klin Monatsbl Augenheilkd. 1984;184:494-498. French.

5. Friedlaender MH. The current and future therapy of allergic conjunctivitis. Curr Opin Ophthalmol. 1998;9:54-58.

6. Friedlaender M. Overview of ocular allergy treatment. Curr Allergy Asthma Rep. 2001;1:375-379.

7. Sancilio LF, Nolan JC, Wagner LE, Ward JW. The analgesic and antiinflammatory activity and pharmacologic properties of bromfenac. Arzneimittelforschung. 1987;37:513-519.

8. Miyake-Kashima M, Takano Y, Tanaka M, et al. Comparison of $0.1 \%$ bromfenac sodium and $0.1 \%$ pemirolast potassium for the treatment of allergic conjunctivitis. Jpn J Ophthalmol. 2004;48:587-590.

9. Hayasaka Y, Yayasaka S, Zhang X, Nagaki Y. Effects of topical corticosteroids and nonsteroidal anti-inflammatory drugs on prostaglandin $\mathrm{E}_{2}$-induced aqueous flare elevation in pigmented rabbits. Ophthalmic Res. 2003;35:341-344. 
10. Asai T, Nakagami T, Mochizuki M, Hata N, Tsuchiya T, Hotta Y. Three cases of corneal melting after instillation of a new nonsteroidal antiinflammatory drug. Cornea. 2006;25:224-227.

11. Isawi H, Dhaliwal DK. Corneal melting and perforation in Stevens Johnson syndrome following topical bromfenac use. J Cataract Refract Surg. 2007;33:1644-1646.

12. Szerenyi K, Sorken K, Garbus JJ, Lee M, McDonnell PJ. Decrease in normal human corneal sensitivity with topical diclofenac sodium. Am J Ophthalmol. 1994;118:312-315.

13. Seitz B, Sorken K, LaBree LD, Garbus JJ, McDonnell PJ. Corneal sensitivity and burning sensation. Comparing topical ketorolac and diclofenac. Arch Ophthalmol. 1996;114:921-924.

14. Moses PL, Schroeder B, Alkhatib O, Ferrentino N, Suppan T, Lidofsky SD. Severe hepatotoxicity associated with bromfenac sodium. Am J Gastroenterol. 1999;94:1393-1396.
15. Rabkin J, Smith MJ, Orloff SL, Corless CL, Stenzel P, Olyaei A. Fatal fulminant hepatitis associated with bromfenac use. Ann Pharmacol. 1999;33:945-947.

16. Uchio E, Itoh Y, Kadonosono K. Topical bromfenac sodium for longterm management of vernal keratoconjunctivitis. Ophthalmologica. 2007;221:153-158.

17. Sharir M. Exacerbation of asthma by topical diclofenac. Arch Ophthalmol. 1997;115:294-295.

18. Sheehan GJ, Kutzner MR, Chin WD. Acute asthma attack due to ophthalmic indomethacin. Ann Intern Med. 1989;111:337-338.
Clinical Ophthalmology

\section{Publish your work in this journal}

Clinical Ophthalmology is an international, peer-reviewed journal covering all subspecialties within ophthalmology. Key topics include: Optometry; Visual science; Pharmacology and drug therapy in eye diseases; Basic Sciences; Primary and Secondary eye care; Patient Safety and Quality of Care Improvements. This journal is indexed on

\section{Dovepress}

PubMed Central and CAS, and is the official journal of The Society of Clinical Ophthalmology (SCO). The manuscript management system is completely online and includes a very quick and fair peer-review system, which is all easy to use. Visit http://www.dovepress.com/ testimonials.php to read real quotes from published authors. 